\title{
O patrimônio histórico edificado como forma de agregar valor ao turismo: uma análise da paisagem edificada no entorno da Praça Dogello Goss - Concórdia, SC
} The national heritage buildings as a way of adding value to tourism: an analysis of the built landscape surrounding the Dogello Goss Square - Concórdia, SC

Les batiments du patrimoine national comme moyen de valorisation du tourisme: une analyse du paysage construit autour de la place Dogello Goss - Concórdia, SC Los edificios del patrimonio nacional como medio de valoración del turismo: análisis del paisaje construido alrededor de la plaza Dogello Goss - Concórdia, SC

\author{
Rudinei Carlos Scaranto Dazzi* \\ Josildete Pereira de Oliveira**
}

Recebido em 16/2/2010; revisado e aprovado em 2/3/2011; aceito em 2/4/2011

\begin{abstract}
Resumo: A influência da globalização na atividade turística propicia a necessidade de estratégias que venham a conduzir tal atividade para satisfazer o público alvo. A paisagem edificada é um dos elementos que proporcionam qualidade turística e cultural, onde a presente pesquisa tem como obj etivo analisar o estudo de caso da paisagem urbana edificada de Concórdia, SC, no recorte da Praça Dogello Goss e seu entorno, enquanto atrativo turístico. Nesta pesquisa, procura-se entender e explicar, por meio da análise descritiva e documental.

Palavras-chave: Patrimônio histórico cultural. Concórdia, SC. Praça Dogello Goss.

Abstract: The influence of globalization on tourism promotes the need for strategies that will lead such activity into meeting its target audience. The built landscape is one of the elements that promote quality of tourism and culture. In this research it has been sought to understand and explain the perception of residents and tourists as for the attractiveness of the studied space.

Key words: National heritage building. Concórdia, SC. Dogello Goss Square.

Résumé: L'influence de la mondialisation sur le tourisme fait nécessaire le développement des stratégies qui mèneront cette activité au rencontre de son public ciblé. Les bâtiments sont un des éléments qui favorisent la qualité du tourisme et de la culture. Dans cette recherche on a cherché à comprendre et à expliquer la perception des résidents et des touristes sur l'attractivité de l'espace étudié.

Mots-clés: Bâtiments du patrimoine national. Concórdia, SC. Place Dogello Goss.

Resumen: La influencia de la globalización sobre el turismo hace necesario el desarrollo de estrategias que lleven a esta actividad hacia el encuentro con su público. Los edificios son uno de los elementos que favorecen la calidad del turismo y de la cultura. En esta investigación se ha tratado de comprender y explicar la percepción de los residentes y de los turistas sobre la actividad del área estudiada.

Palabras clave: Edificios del Patrimonio Nacional. Concórdia, SC. Plaza Dogello Goss.
\end{abstract}

\section{Introdução}

Ao se investigar a natureza de um núcleo urbano, percebe-se que a formação do seu centro histórico surge a partir de sua constituição inicial, e a ocupação deste espaço passa por transformações ao longo do tempo. A cidade contemporânea emerge desse centro que precisa ser preservado como um todo, sendo os pontos de interesse identificados e analisados na conjuntura da paisagem.

Esta pesquisa explora o conceito de paisagem urbana e turismo, as relações culturais como forma de conhecimento dos bens materiais produzidos pelo homem, bem como, as transformações que o mesmo causa na paisagem. Para que se entenda a paisagem urbana, os bens materiais precisam ser preservados em seu conjunto. As políticas públicas promovem a preservação dos bens culturais a partir de um processo individual, permitindo a perpetuação da paisagem como um todo.

Assim, o estudo objetiva analisar a evolução morfológica da paisagem urbana edificada do município de Concórdia, SC, com um recorte voltado à Praça Dogello Goss e seu entorno, verificando o potencial turístico da paisagem através do olhar de residentes

\footnotetext{
* Mestre em Turismo e Hotelaria da Universidade do Vale do Itajaí (UNIVALI/SC).

** Professora do Curso de Mestrado em Turismo e Hotelaria da Universidade do Vale do Itajaí (UNIVALI/SC). Doutora em Geografia e Mestre em DEA - Nature Envaironnement Societé (Université de Ca em Basse Normandie, França). Graduada em Arquitetura e Urbanismo pela Universidade Federal da Bahia (UFBA/BA).
} 
e turistas. O estudo apoiou-se em pesquisas documentais, bibliográficas e iconográficas.

Para compreender essa dinâmica optou-se por uma abordagem metodológica, segundo a visão serial proposta por Cullen (1971), que possibilita ao observador múltiplas leituras do espaço, penetrando neste mundo de sensações e percepções únicas. As imagens reveladas pelos residentes e turistas, serão analisadas segundo essa abordagem, onde Cullen (1971) destaca três aspectos: a óptica, o local e o conteúdo. A ótica destaca a paisagem urbana como uma sucessão de surpresas; o local refere-se às reações frente à posição no espaço, a inter-relação do aqui e o ali, que produz belos efeitos urbanos e; o conteúdo refere-se à relação da textura, escala, cor, traçado e estilo em seus processos evolutivos.

Segundo Cullen (1971) a paisagem em uma cidade não existe simplesmente para ser vista, mas também para ser descoberta, explorada, analisada, percorrida pelo observador, a fim de buscar sua história, sua memória, ou seja, seus registros de passado e presente que, juntos, formam um atrativo turístico.

Já a atividade turística é definida como

[...] o movimento de pessoas, por tempo determinado, para a destinação fora do seu local de residência, e as atividades realizadas durante o tempo de permanência nas localidades visitadas. (TREMBLAY, 2000, p. 25).

ocasionando uma nova compreensão do espaço urbano, em especial pelas edificações históricas que fazem parte deste contexto. Deste modo, surge o interesse em compreender o potencial turístico através da paisagem edificada da Praça Dogello Goss do Município de Concórdia, SC.

Dessa forma, o presente estudo buscou extrair, através de imagens, informações que são intrínsecas na percepção do residente e do turista, as quais se realizadas de forma oral, muitas vezes não expressariam a visão na íntegra dos respondentes. A seleção dos participantes foi aleatória e realizada por meio de duas inserções no município de Concórdia, no mês de agosto e setembro de 2008, quando o pesquisador esteve no núcleo central da Praça Dogello Goss, onde 26 pessoas que adentravam nesta área central foram convidadas para participar da pesquisa após a explicação dos objetivos. A escolha aleatória dos respondentes ocorreu em função de tomar o grupo heterogêneo quanto à faixa etária, condição social, nível de formação cultural, possibilitando leituras variadas do mesmo espaço, sem condicionar as respostas, na tentativa de realizar a análise deste objeto de estudo sem interferência do pesquisador. Os entrevistados foram divididos em dois grupos, 13 residentes e 13 turistas, procedimento adotado em função de a Praça ser um marco referencial para os residentes e ponto central do município para os turistas.

Por fim, solicitou-se aos respondentes (turistas e residentes) que fizessem dez fotos da Praça e seu entorno com a máquina fotográfica do pesquisador, segundo a percepção que eles (respondentes) tinham do espaço, de forma livre e sem qualquer interferência, para não haver indução das imagens. Após o registro das imagens, o pesquisador enviou, por meio eletrônico, uma entrevista composta de cinco questões em formulário específico, composto pelas dez imagens fotográficas registradas pelo próprio respondente, solicitando que o mesmo escolhesse apenas uma das imagens para, então, responder a entrevista inclusa no formulário.

Portanto, fundamenta-se a preeminência da abordagem por ser considerada uma interessante referencia para a análise do turismo, uma vez que a paisagem edificada influencia a capacidade de atrair o visitante, promovendo o destino, e, em consequência, contemplando toda a cadeia produtiva do setor.

\section{Caracterização histórica e espacial da cidade de Concórdia}

O município de Concórdia situa-se na região oeste catarinense, na microrregião do Alto Uruguai, a $493 \mathrm{~km}$ de Florianópolis, onde sua colonização ocorreu com a vinda, a partir de 1910, de imigrantes italianos e alemães, provenientes, na sua grande maioria do Rio Grande do Sul, que foram chegando com suas famílias e instalando-se na margem direita do Rio Uruguai, em busca de terras melhores para o plantio e a pecuária, além da possibilidade de trabalharem junto à empresa Brazil Development Colonization Company, na construção da estrada de ferro São Paulo - 
Rio Grande do Sul, que tinha como principal finalidade, delimitar as fronteiras entre Brasil e Argentina (PREFEITURA MUNICIPAL DE CONCÓRDIA, 2008).

Concórdia faz parte da região onde aconteceu a Guerra do Contestado ${ }^{1}$, que manteve em ebulição o planalto catarinense e paranaense de 1912 a 1916, foi o resultado do acúmulo de injustiças sociais sofridas, por décadas, pela população sertaneja da região. As tensões advinham, principalmente, do anseio por um pedaço de terra, bem-estar e segurança para as famílias camponesas. Dominada por coronéis e negligenciada pelos governantes, essa região foi o cenário de uma das mais sangrentas rebeliões ocorridas no Brasil republicano, com um saldo de cerca de seis mil sertanejos e mil soldados do governo mortos. O estopim foi a imensa concessão dada em 1908 à empresa inglesa Brazil Railway Company, do empresário Percival Faquhar (dono da Madeira-Mamoré e da Port-of-Pa-rá), para a construção da estrada de ferro São Paulo-Rio Grande do Sul. O acordo dava à empresa 15 quilômetros de terra para ambos os lados dos trilhos (sinuosos, por coincidência) e que passariam exatamente sobre o território contestado. Mais de $34 \mathrm{mil}$ quilômetros quadrados de presente para estrangeiros (LAPS, 2003).

Nesta época, o governo estadual em parceria com o governo federal estimulou a venda de pequenas propriedades rurais aos colonos gaúchos de origem italiana e alemã, que se dedicavam à agricultura e à criação de suínos. Até então, a região era habitada somente por caboclos. A partir de 1922, a Sociedade Territorial Mosele Eberle Ahrnons \& Cia, passou a vender (oferecendo muitas facilidades) terras em pequenas extensões

\footnotetext{
${ }^{1}$ A Guerra do Contestado ocorreu no início do século XX, entre 1912 e 1916, na área então disputada pelos estados do Paraná e Santa Catarina, denominada região do Contestado, uma luta camponesa pela posse da terra que levou às armas cerca de 20 mil pessoas, gerando um dos maiores conflitos, sociais da história do país. Os caboclos, população que habitava a região oeste de Santa Catarina, se revoltaram contra os governos estaduais, que promoviam a concentração da terra em benefício dos grandes fazendeiros. A revolta também ocorreu contra o governo federal, que concedeu uma extensa área de terra à empresa norte-americana - Brazil Railway Company - responsável pela construção do trecho da Estrada de Ferro São Paulo - Rio Grande, a qual ligava o sul com o sudeste do Brasil (AMADOR, 2010).
}

(PREFEITURA MUNICIPAL DE CONCÓRDIA, 2008).

Esses imigrantes de origem italiana e alemã marcaram evidentemente a arquitetura do município, proporcionando um conjunto paisagístico em consonância com as colinas que se fazem presentes no entorno da cidade, assim como, trouxeram seus costumes e cultura, que eram distintos aos hábitos caboclos e dos povos indígenas existentes.

Em 1925, a colônia conhecida, até então, pelo nome de Queimados, passa a ser chamada de Colônia Concórdia, por iniciativa da Sociedade Territorial Mosele Eberl, Ahrons \& Cia. O nome Concórdia deve-se ao fato de um acordo de paz, estabelecido entre os jagunços, liderados por José Fabrício das Neves, líder da Guerra do Contestado, e a Brazil Development Colonization Company. Outro fato que motivou a mudança do nome da Vila Queimados foi por aquele exercer uma força psicológica negativa muito forte sobre os moradores, devido ás inúmeras lendas contadas na região. Contavam que o nome havia sido dado ao rio, que cortava a vila, por funcionar como depósito de caboclos mortos, que eram queimados antes de serem jogados em suas águas. Para outros, eram os cadáveres de caboclos abandonados, sem famílias, após lutas entre grupos rivais e queimados vivos a mando de José Fabrício das Neves (PREFEITURA MUNICIPAL DE CONCÓRDIA, 2008). O nome "Queimados" permanece nominando o rio que corta a cidade - Rio dos Queimados.

A consolidação do desenvolvimento da cidade ocorreu após a instalação das estradas de rodagem, que buscavam principalmente e escoamento agrícola e o extrativismo da madeira, exportada para a Argentina, por meio do Rio Uruguai.

Mais tarde, em 29 de julho de 1934, foi emancipado politicamente, passando a ter desenvolvimento próprio. Atualmente possui uma área de $797,26 \mathrm{~km}^{2}$, e uma população de 64.058 habitantes (IBGE, 2008). Sendo que, $71,76 \%$ da população vivem no perímetro urbano, e $28,23 \%$ no perímetro rural. Desta população, 46.136 são eleitores do município.

As principais edificações foram projetadas e construídas pelo imigrante italiano e arquiteto-construtor Leônidas Fávero, que deu forma a configuração urbana da cidade, no início da década de 1940, em que Dazzi 
(1999) complementa que estes traços ainda permanecem perceptíveis na cidade e no interior, onde formam um conjunto que um observador sensível e disposto percebe aspectos os naturais e construídos na paisagem, ora bucólica, com sua ondulação verde, ora lúdica, em suas casinhas na maioria de madeira, dispostas simetricamente.

\section{Caracterização socioeconômica}

A economia do Município tem por base a agroindústria, predominando a suinocultura, avicultura, pecuária de leite, culturas agrícolas e indústria alimentícia. Tendo como principal característica a estrutura rural, o município de Concórdia é formado basicamente por minifúndios. Possui uma área industrial de $207.000 \mathrm{~m}^{2}$, localizada nas margens da BR 153, proximidades da sede, com infra-estrutura básica para a instalação de novas empresas. Atualmente, Concórdia é a $12^{\text {a }}$ Economia do Estado, com uma taxa de crescimento anual de 2,91\% (IBGE, 2008). O produto Interno Bruto (PIB) do Município de Concórdia é elevado, sendo de $\mathrm{R} \$ 13.715,00$ per capita/ano. Dentre os 5.507 municípios brasileiros, ocupa a 32a posição no Índice de Desenvolvimento Humano (IDH), e no Estado ocupa a $13^{\circ}$ lugar - IDH (2002), e a 12ª posição no Îndice de Desenvolvimento Social (IDS) (Secretaria de Estado de Desenvolvimento Urbano e Meio Ambiente), entre os 293 municípios de Santa Catarina.

O município recebeu em 2002 o $1^{\circ}$ lugar do país no Prêmio de Gestão Fiscal responsável; na área de tecnologia, Concórdia possui o Centro Nacional de Pesquisa de Suínos e Aves, com sede na Empresa Brasileira de Pesquisa Agropecuária (EMPRAPA), sendo conhecida nacionalmente como a Capital da suinocultura. Ainda na tecnologia, Concórdia é pioneira no país na educação para o transporte, através da Fundação Adolpho Bósio de Educação no Transporte (FABET). Também no Município, está instalado o maior frigorífico da América Latina, a Empresa SADIA, conhecida no Brasil e no mundo.

Na economia urbana, o comércio é forte e bem estruturado. No setor de serviços, destacam-se o transporte, a educação técnica e superior e, a saúde, todos com faturamento expressivo e alta qualificação. O Município tem sua economia bastante concentrada no "cluster" agroindustrial, com uma razão de dependência de 60 a 70\% do movimento econômico. A meta é diversificar a base econômi$\mathrm{ca}$, fomentando outras atividades potenciais dentro da vocação de Concórdia: tecnológico na área de informática, os setores moveleiro, metal-mecânica, têxtil e construção civil, sem, no entanto, descuidar-nos da nossa grande vocação, o Agronegócio.

O mercado consumidor possui bom potencial, dada a renda per capita e os valores da cultura local, que privilegiam a adimplência. Tem também um excelente estoque de capital nos bancos, com poupança de aproximadamente $\mathrm{R} \$ 80$ milhões. Na área de pesquisa e desenvolvimento, destacam-se duas importantes instituições: a EMBRAPA e o Centro Nacional de Pesquisa de Suínos e Aves de Concórdia (CNPSA), que atende a todo o sistema agroindustrial familiar e de destaque Nacional e Internacional (SADIA, PERDIGÃO, CHAPECÓ, AURORA) e a Universidade do Contestado (UNC), que possui curso de Tecnólogo em Informática, provendo os recursos humanos com a necessária qualificação. No tocante à intervenção do Serviço Brasileiro de Apoio às Micro e Pequenas Empresas (SEBRAE), há no município uma agência de articulação, que atende os quinze municípios da Associação dos Municípios do Alto Uruguai Catarinense (AMAUC).

Desenvolve ações diretas com os empreendedores e empresários da região, através de entidades credenciadas (ACIs e CDLs, Sindicato dos Produtores Rurais), e também parcerias com Prefeituras Municipais, como: realização de cursos de gestão empresarial (marketing, custos e finanças, empreendedorismo, entre outros), qualidade total (capacitação de produtores rurais, em parceria com a Copérdia); mobilizando empresários / empreendedores em missões empresariais para conhecer feiras e novas oportunidades de negócios; constantes treinamentos e consultorias para empresas da área rural, já que o município tem forte vocação no empreendedorismo rural e com isso constantemente os empresários do setor têm tido oportunidade de se reciclarem e estarem recebendo metodologias e conhecimento para gestão de seu negócio; apoio à criação de uma ONG de microcrédito (CREDICERTO); prospecção de 
recursos junto a outras instituições financeiras; palestras e consultorias coletivas de orientação ao empresariado para a visão estratégica e competitiva do seu negócio.

\section{Praça Dogello Goss no contexto do cenário urbano de Concórdia}

A preservação das edificações, bem como a paisagem urbana no seu conjunto, valoriza a cultura local, resgata os valores culturais e possibilita a formatação de um produto turístico, sendo que "[...] esse patrimônio histórico arquitetônico interessa ao turismo urbano, pois pode representar uma possibilidade de diversificação da oferta turística do lugar" (CRUZ, 2002, p. 52). Portanto, este estudo poderá contribuir para o incremento de uma nova atividade econômica, no caso o turismo, utilizando o potencial arquitetônico e urbanístico da cidade como um perfeito atrativo turístico.

Afirma-se, então, que a paisagem, inserida neste contexto, é um dos segmentos da atratividade, fundamental para a construção de um produto turístico. As cidades apresentam elementos regionais de uma cultura, únicos, singulares, importantes para a regionalização do turismo, preservando suas rugosidades, suas características, sua memória, sua cultura.

Ter cultura significa, do ponto de vista do senso comum, possuir um certo conjunto de conhecimentos ou informações que não são utilizados no dia-a-dia das pessoas comuns e, ao mesmo tempo, ser dotado de uma capacidade especial para apreciar e usar o patrimônio. (DURHAM, 1984, p. 24).

As mudanças decorrentes dos fatos históricos e da urbanização sem regras geram uma transformação da paisagem urbana e, a Praça Dogello Goss é um exemplo disso, pois a mesma é ponto de referencia da cidade.

Ressalta-se que a Praça torna-se palco das manifestações políticos/culturais da cidade e menciona essas transformações por meio da paisagem. A sociedade passa então a conviver com situações que, em alguns momentos, não podem ser modificadas. A evolução se torna necessária, mesmo que o progresso não permita que se mantenha na totalidade o conjunto edificado, o que muitas vezes não é benéfico para a sociedade e suas as relações sociais com o meio construído.
Assim, a compreensão dos valores sócioeconômicos, históricos e culturais da cidade se torna pertinente para a identificação dos modos de uso indicados para esse espaço, quer seja por residentes, quer seja por turistas.

A organização espacial da paisagem com os elementos construídos revelam a evolução e a história da população envolvida, sendo que seus estilos e períodos levam a múltiplas leituras. A paisagem urbana é uma sucessão de surpresas, conduzindo o visitante a percepções únicas, estimulando-o a percorrer novos espaços. A personalidade do local e a interação do visitante com a paisagem é única e produzem sensações que serão repassadas a outros turistas e também aos residentes. As edificações antigas são admiradas, quando preservadas e; com os novos usos que possibilitam o residente e o turista interagirem e desvendarem estes espaços.

Nesse sentido, cita-se os indicadores de competitividade de destinações turísticas baseados no modelo de Dwyer e Kim (2003): recursos herdados e recursos criados. Para os autores, os recursos herdados aparecem em forma de recurso natural, definindo a estrutura do ambiente, englobando o clima, a flora, a fauna e outros aspectos físicos da destinação e; também figuram a cultura e o patrimônio local (DWYER; KIM, 2003). Murphy et al. (2000) afirmam que cultura e patrimônio são uma força para atrair o visitante. Outrossim, os recursos criados são todos os serviços e equipamentos disponibilizados para o desenvolvimento da atividade turística (DWYER; KIM, 2003). De acordo com Cooper et al. (1996), são os recursos naturais, incluso cultura e patrimônio que garantem a atratividade em relação ao visitante, mostrando-se como uma faceta de prosperidade local e regional.

A Praça Dogello Goss e seu entorno, objeto deste estudo, estão pontuados de edificações e elementos escultóricos que marcam a evolução da cidade de Concórdia, revelando uma história de luta, glória e desenvolvimento. Do período do Contestado, onde conflitos foram deflagrados, a colonização, com a chegada de imigrantes e migrantes italianos e alemães, da "concórdia" entre eles, que gerou o nome da cidade, aos poucos esta paisagem foi se transformando. Onde antes havia apenas terra e grama riscadas por conflitos, surge a praça com arruamento tosco em seu entorno, recebendo construções de madeira, como a 
primeira igreja católica. A praça da pequena vila foi mudando e definindo a sua estrutura espacial, que no ano de 1969 tem seu traçado definitivo com um chafariz ao centro e uma concha acústica onde manifestações artísticas e políticas são organizadas, tornado-se o ponto de encontro de residentes e turistas. O chafariz com suas águas coloridas à noite que se projetam ao céu proporcionando um espetáculo de cores e movimentos, fazendo com que os visitantes no inicio tentassem, em frascos de vidro, levar um pouco daquela água colorida.

A Praça Dogello Goss é o principal cartão-postal da cidade. Inicialmente, no ano de 1926, a praça já constava na planta da cidade, assinada pelo engenheiro Homero Araújo, se chamava Santos Dumont, medindo $100 \mathrm{~m} \times 100 \mathrm{~m}$, e onde os terrenos nas ruas perimetrais da praça eram os mais habitados. Mais tarde, após a emancipação do município, o Prefeito Dogello Goss resolveu "rebaixar" a altura da praça e aterrar o terreno onde fica o Fórum e o Colégio Deodoro.

As árvores foram retiradas do terreno e no centro foi erguido um mastro, para hasteamento da bandeira nacional. Com este fato, $\mathrm{o}$ local passou a se chamar Praça da Bandeira. No ano de 1940, com o auxílio do comerciante Caetano Chiuchetta, foram plantadas árvores na praça, sendo que duas delas existem até hoje. Na gestão seguinte, a praça ganhou postes de iluminação e bancos de concreto. A atual forma e denominação da praça ocorreram no ano de 1969, com a construção do chafariz, concha acústica, com sala de música e os sanitários públicos, uma fonte sonoro-luminosa, arborização organizada em canteiros, além de um parque infantil (PREFEITURA MUNICIPAL DE CONCÓRDIA, 2008).

\section{Análise da paisagem edificada}

A escolha do universo de pesquisa, no caso desta investigação, se fez para delimitar a área a ser estudada, o que possibilita uma análise mais detalhada, focando apenas no objeto de estudo, a Praça Dogello Goss e seu entorno. A escolha em analisar a paisagem edificada da área central da cidade, ocorre como ferramenta, que possibilita a ponderação deste objeto tornar-se um agregador de valor para o turismo.

O conceito da "Visão Serial" de Cullen (1971), empregado para analisar as imagens deste estudo: a Óptica, o Local e o Conteúdo, por meio de registro fotográfico e, o discurso (DSC's) de Lefèvre e Lefèvre (2003), como forma de representação interpretativa, enquanto mediador de leitura, significação e representação do real. Foram criadas cinco categorias para atender aos objetivos da pesquisa, sendo elas:

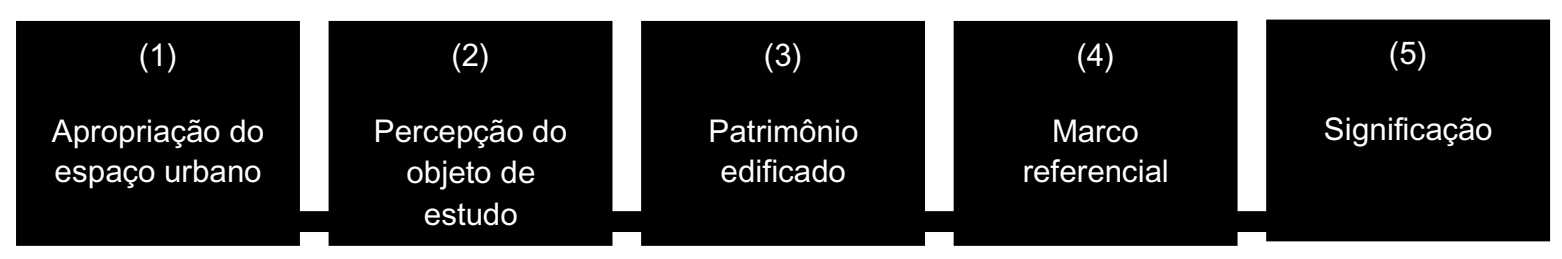

A primeira categoria trata da (1) apropriação do espaço urbano, que traz os elementos constituintes da morfologia urbana descrito por Lamas (2004). A segunda categoria é a (2) percepção do objeto de estudo, que inclui o pensamento e as ações, que Santaella (2000) interpreta como algo diverso da significação, onde o próprio objeto irá determinar a representação, seja ela externa ou imediata ao objeto, no qual o juízo é formulado a partir da percepção. A terceira categoria contempla o (3) patrimônio edificado, que de acordo com Yázigi (2001) e Choay (2001) pode servir como identificador de monumentalidade. Boullón (1985) dará suporte a quarta categoria (4) marco referencial e, a última categoria, a da (5) significação, constitui uma idéia, uma representação mental, ou seja, uma copia de objetos concretos, que de acordo com Santaella (2000), os signos não são capazes de abarcar a totalidade do objeto representado apenas um determinado aspecto, podendo afirmar, que não existe um limite de interpretações possíveis sob um mesmo objeto, sendo que o mesmo pode gerar diferentes significados. 
Neste sentido, o conceito de Cullen (1971) vem corroborar com os demais autores utilizados como arcabouço para elencar as categorias de análise, dando sentido a interpretação da paisagem urbana como uma sucessão de surpresas e pontos de vista diferentes.

\section{Mapeamento da potencialidade de atratividade turística: olhar de residentes e turistas}

De acordo com as imagens registradas por residentes e turistas e pelas informações extraídas dos DSC's observa-se que em relação a percepção da significação da imagem, encontramos pontos de encontro nos discursos dos dois grupos estudados o gerou um mapa das potencialidades turísticas para a cidade de Concórdia no recorte da Praça Dogello Goss e entorno.

Berque (1998) adota o sentido psicológico da visão, isto é, situa os indivíduos no seio de uma cultura, dando com isso, um sentido à sua relação com o mundo. $\mathrm{O}$ sentido que não é o mesmo para cada individuo, pois depende da percepção da formação cultural de cada um, onde as construções mentais, de importância insubstituível, apresentam característica de não permanecer no tempo, nem se generalizam para todos.

Com relação aos bancos da Praça Dogello Goss encontramos o registro da imagem extraída do discurso do residente pontuando que esta "[...] durante muito tempo fez parte do meu cotidiano. Era a vista que tinha do meu trabalho durante mais de 20 anos [...]" (Residente 1). Já para o turista a significação é dada pela "[...] melancolia de uma cidade que apesar de seu desenvolvimento econômico, apresenta traços de cidade interiorana, com espaços agradáveis que convidam o visitante a sentar e apreciar" (Turista 3). Outro ponto que coincidem os discursos e imagens são em relação às fotos em que o residente relata " [...] o Leão Alado nos remete a cultura italiana tão importante para a nossa região" (Residente 8); discurso que aparece na fala do turista "[...] é prova da presença veneziana no município de Concórdia" (Turista 8).

A paisagem natural é também percebida por residentes e turistas quanto a significação, que aponta a imagem como: "[...] faz lembrar a infância, pois atualmente são poucos os lugares que temos o contato com a natureza." (Residente 2); “[...] árvore símbolo como plano de fundo e suas 'veias' de segurança para a tecnologia da iluminação elétrica." (Residente 4); "[...] a árvore além de ser patrimônio histórico eu fotografei junto dela os meus filhos quando crianças" (Residente 5). Para o turista: "[...] a imagem da grande figueira representa bem a cidade, uma árvore nova, frondosa e bem cuidada, amparada ara poder se manter" (Turista 2). A cidade pequena ou não, é um espaço que pulsa, seduz e incomoda os atores que nela participam, conforme citado por Castrogiovanni (2001). O autor coloca que a cidade depende do observador e de suas informações para percebê-la, além do que os olhos podem ver.

Para o residente as construções no entorno da Praça são importantes espaços de referência histórica como podemos observar “[...] a escola Deodoro, a antiga casa dos Irmãos Lassalistas, e parte da Prefeitura, alguns já foram tombados, outros falta conscientização para que isso ocorra" (Residente 6), opinião compartilhada pelo Turista 8 quando cita: "[...] significa a posição social que o seu proprietário possuía, na ocasião da construção", o mesmo ocorre com a edificação da antiga farmácia Santo Antonio, antigo Fórum e Colégio Deodoro assinalados por residentes e turistas como edificações de interesse histórico para a população local e região.

O chafariz surge em muitos discursos de residentes e turistas, mas como imagem significativa aparece apenas aos residentes dando sentido aos mesmos, em suas memórias afetivas, demonstrado pelo no discurso do Residente 7 que cita "[...] quando conheci Concórdia, em 1994, uma das coisas que mais me chamou atenção foi o chafariz [...]"; e confirmado pelo Residente 10 "[...] era o ponto de encontro nas tardes, com musicas e as águas coloridas do chafariz".

Pela análise das imagens percebe-se que a praça com seus aspectos naturais e construídos é o ponto onde residentes e turistas atribuem maior significação, para residentes pela memória e vivencias neste local, para turistas por ser um ponto central de fácil percepção no meio da massa edificada das construções. 


\section{Considerações finais}

O objeto de estudo a Praça Dogello Goss e seu entorno, foi analisada por meio das modificações e transformações ocorridas ao longo do tempo, pelas suas memórias, vivencias que são pontuadas na paisagem da cidade de Concórdia. Ao longo do desenvolvimento desta pesquisa, foi possível observar que as características morfológicas da cidade de Concórdia condicionaram a sua evolução, a Praça teve seu traçado alterado, porém seu formato de $100 \mathrm{~m}$ X 100m permaneceu inalterado, uma vez que não havia espaço físico para que se modificasse esse contexto.

Sendo a paisagem formada por fatos do passado e do presente, a compreensão da organização espacial, bem como de sua evolução, só se torna possível mediante a acurada interpretação do processo dialético através do tempo, pelas categorias de análise empregadas nesta pesquisa - Óptica, Local e Conteúdo, conforme Cullen (1971).

O Local compreende o aspecto visível de uma coisa. A Óptica pode ser entendida como uma tarefa ou atividade esperada de uma forma, pessoa, instituição ou coisa. $\mathrm{O}$ Conteúdo implica a inter-relação de todas as partes de um todo, o modo de organização ou construção. O processo pode ser definido como uma ação continua, desenvolvendo-se em direção a um resultado qualquer, implicando conceitos de tempo e mudança. Assim percebe-se que a função está diretamente relacionada com sua forma, portanto, é vista como uma atividade elementar de que a forma se reveste.

Existe um conjunto arquitetônico que se preservado e restaurado ainda pode tornar-se um atrativo turístico para residentes e turistas, percebido por parte dos respondentes. $\mathrm{O}$ espaço urbano possui relação direta com a atividade turística, como produto para visitação onde os elementos da paisagem passam significados que são essenciais, na qualificação deste espaço para a prática do turismo, não apenas por sua dinâmica social e cultural, mas por seus históricos. Wainberg (2000) pontua que o turista busca os elementos da paisagem, os espaços construídos, o movimento da vida e, da cultura do local visitado.

Para se compreender o espaço social em qualquer tempo, é fundamental tomar em conjunto o Local, a Óptica e o Conteúdo, como se tratasse de um conceito único. Não se pode analisar o espaço por meio de um só desses conceitos, ou mesmo de uma combinação de dois deles. Se examinarmos apenas a Óptica e o Conteúdo, eliminando o Local, perderemos a história da totalidade espacial, simplesmente porque a Óptica não se repete duas vezes. Separando o Conteúdo e Óptica, o passado e o presente são suprimidos, com o que a idéia de transformação nos escapa e as instituições se tornam incapazes de projetar-se no futuro. Examinar Local e Óptica sem Conteúdo pode resultar na compreensão de uma sociedade inteiramente estática, destituída de qualquer ação.

O arcabouço teórico utilizado serviu para que se obtivessem respostas mais precisas quanto à análise da paisagem da Praça Dogello Goss e seu entorno. Autores como Cullen (1971), Boullón (1985), Yázigi (2001) Santanaella e Noth (1998), Castrogiovani (2001) e Lefévre e Lefévre (2003; 2005), foram utilizados dialogando entre si, com o propósito de verificar o potencial turístico do objeto de estudo.

O turismo é o setor que mais cresce em toda sociedade, indiferente a escassez histórica, os países estão se abrindo para o turismo. Trigo (1996) destaca que o interesse das pessoas pela história, arte e cultura em geral tem gerado grandes projetos integrando turismo e cultura. A paisagem urbana de Concórdia possui símbolos que percebidos pelos turistas podem produzir um novo descobrimento, um renascer da cidade. Apesar de sua verticalização, a cidade ainda produz momentos de pura contemplação, bucólica e interiorana, que refletem as características da cultura local.

A arquitetura religiosa é marcada por muitos santuários circunscritos na área urbana, como também pela igreja de Pinheiro Preto, relocação bem sucedida com arquitetura em madeira e que hoje serve como museu. Também na área urbana esta o Memorial Attílio Fontana - espaço cultural e de grande afluxo de residentes e visitantes e o museu municipal Hermano Zanoni.

A Praça Dogello Goss, com sua fonte sonora luminosa e seu entorno com bens tombados, é um dos marcos referenciais da cidade de Concórdia e muito utilizada pela 
comunidade em eventos e manifestações artísticas, culturais e políticas.

Constatou-se que o município possui uma eficiente e atrativa rede de hotéis para o conforto dos turistas, como também restaurantes temáticos com boa gastronomia. Conta com o Convention E Visitors Bureau Águas do Alto Uruguai que proporciona a divulgação do município em feiras e eventos relacionados ao turismo. No entanto, percebe-se que a cidade não atenta para a potencialidade e o significado de sua paisagem urbana como atrativo turístico. No momento, apenas veicula duas rotas no interior do município como turísticas: Caminho do Engenho e Caminho da Roça. A sede do Convention \& Visitors Bureau está no entorno da Praça Dogello Goss e as saídas para as rotas mencionadas também se dão na praça, o que ratifica esta análise de potencial turístico.

Quando os residentes e turistas percorrem os espaços da Praça e seu entorno, descobrem múltiplas sensações percebendo a cidade como uma ocorrência emocionante no meio em que se situa. Pela semiótica compreende-se os marcos referenciais, os signos contidos nas imagens registradas que relacionam as características afetivo-simbólicas destes elementos que compõem a paisagem.

As imagens e imaginário dos registros de residentes e turistas ampliam a discussão da valoração do patrimônio arquitetônico bem como do conjunto da paisagem e pela busca da identidade do local, sem esquecer a legislação que trás as questões da aplicação da lei na preservação e conservação de bens de interesse histórico. A questão patrimônio teve seu inicio com Dom Pedro II, mas efetivamente é retomado nos anos de 1920 com a Semana de 22 com o Movimento Modernista no Brasil. Desse modo, se faz necessário estabelecer uma política de incentivos que estimulem a preservação de fato destas edificações de interesse histórico cultural para o município.

Para os residentes, a Praça Dogello Goss se apresenta como um espaço de encontro, lazer, memória onde muito de suas vivencias na cidade passam por ela, bem como, seu entorno está marcado na memória que por meio da lente fotográfica foram externadas, muitas dessas imagens foram negligenciada pela correria do dia. Outra observação é em relação à importância de manter viva essa paisagem, cobrando ações por parte dos órgãos competentes. A nostalgia suscitada por residente faz perceber que em um espaço, pode-se perceber cargas informativas, que através do tempo devem ser preservadas para que se consiga uma leitura histórico-cultural, onde esses atores conseguem reconhecer e dar sentido ao seu dia a dia.

Pelo olhar dos turistas, tem-se dois grupos, o primeiro percebe a Praça com identidade, como uma cidade portadora de historicidade e o segundo aponta como um não lugar, que poderia estar em qualquer cidade, pois não percebem os traços únicos que fazem referencia a cultura local. Mas, ressalta a percepção dos respondentes turistas de que a Praça é um espaço de atratividade turística. Haja vista que, mesmo não possuindo uma ligação cultural, emocional com o objeto, os turistas buscam desvendar os mistérios, a história contida nestes espaços, uma busca mágica, que possa identificar a forma de viver desses atores, fazendo com que seu cotidiano passe a ser o do visitante em questão. Essa identificação possibilita uma opinião mais crítica em relação ao espaço e contribuiu para que a paisagem se mantenha como atrativo para todos que ali se encontram.

Os dados pesquisados e analisados reforçam a possibilidade da paisagem edificada da Praça Dogello Goss, ser considerada um atrativo turístico. Consequentemente o planejamento de ações integradas, que incluem a Praça na rota com atrativo urbano, é uma alternativa para o incremento do turismo e desenvolvimento local.

\section{Referências}

AMADOR, M. C. P. Guerra do Contestado: marca o fim e o início de modelos de desenvolvimentos na região Oeste Catarinense. In: Cadernos de CEOM, Chapecó, ano 22, n. 31, 2010.

BERQUE, A. Paisagem-marca, paisagem-matriz: elementos da problemática para uma geografia cultural. In: CORRÊA, R.L; ROSENDAHL, Z. (Org.). Paisagem, tempo e cultura. Rio de Janeiro: EdUERJ, 1998. p.84-91.

BOULLÓN, R. C. Planificacion del espacio turístico. Trilas: México, 1985.

CASTROGIOVANNI, A. C. Turismo e ordenação no espaço urbano. In: CASTROGIOVANNI, A. C. (Org.). Turismo urbano. São Paulo: Contexto, 2001.

CHOAY, F. A alegoria do patrimônio. São Paulo: Ed. Unesp, 2001.

COOPER, C. et al. Tourism: principles and practice. 2nd ed. Essex: Longman, 1996. 
CRUZ, R. C. A. As paisagens artificiais criadas pelo turismo. In: YÁZIGI, E. (Org.). Turismo e paisagem. São Paulo: Contexto, 2002.

CULLEN, G. Paisagem urbana. Lisboa: Edições 70, 1971.

DAZZI, R. S. Reminiscenza, reencontrando o passado. Concórdia: Cabeça Oca, 1999.

DURHAM, E. R. Movimentos sociais e a construção da cidadania. Novos Estudos, São Paulo, v. 10, p. 24-31, out. 1984.

DWYER, L.; KIM, C. Destination competitiveness: Determinants and Indicators. Current Issues in Tourism, v. 6, n. 5, 2003.

INSTITUTO Brasileiro de Geografia e Estatística (IBGE). Cidades. Disponível em: <http://www.ibge.gov.br/ cidadesat/default.php>. Acesso em: 3 jun. 2008.

LAMAS, J. M. R. G. Morfologia urbana e desenho da cidade. 3. ed., Lisboa: Fundação Calouste Gulbekian, 2004.

LAPS, L. Os camponeses do Contestado. A nova democracia, ano I, n. 9, maio 2003.

LEFÉVRE, F.; LEFÈVRE A. M. C. Discurso do sujeito coletivo: um novo enfoque em pesquisa qualitativa. Caxias do Sul: EDUCS, 2003. (Coleção Desdobramentos)

. Depoimentos e discursos: uma proposta de análise em pesquisa social. Brasília: Líber, 2005. (Série Pesquisa; 12)

MURPHY, P.; PRITCHARD, M. P.; SMITH, B. The destination product and its impact on traveler perceptions. Tourism Management, v. 21, n. 1, p. 43-52, 2000.

PREFEITURA MUNICIPAL DE CONCÓRDIA. Assessoria de Planejamento-ASPLAN. Disponível em: <http:/ / www.concordia.sc.gov.br/asplan_arquivos.htm\#>. Acesso em: 31 jul. 2008.
. Dados estatísticos. Disponível em: <http://www. concordia.sc.gov.br/>. Acesso em: 13 jun. 2008.

. Secretaria Municipal de Urbanismo de Concórdia. Decreto n. 2.134, de 18 de dezembro de 1984.

. Secretaria Municipal de Urbanismo de Concórdia. Decreto n. 2.892, de 19 de novembro de 1991.

. Secretaria Municipal de Urbanismo de Concórdia. Decreto n. 3.779, de 28 de novembro de 1996.

. Secretaria Municipal de Urbanismo de Concórdia. Lei n. 1.925, de 12 de novembro de 1984. 2008.

Secretaria de Urbanismo e Obras. Plano Diretor,

SANTANAELLA, L.; NOTH, W. Imagem: cognição, semiótica, mídia. São Paulo: Luminuras, 1998.

SANTANAELLA, Lúcia. A teoria geral dos signos: como as linguagens significam as coisas. São Paulo: Pioneira, 2000.

SPOSITO, M. E. B. A urbanização da sociedade: reflexões para um debate sobre as novas formas espaciais. In: DAMIANI, A. L.; CARLOS, A. F. A.; SEABRA, O. C. L. O espaço no século: a nova raridade. São Paulo: Contexto, 1999.

TREMBLAY, P. Glossário. Turismo: visão e ação. Itajaí, SC, v. 2, n. 4, p. 25, fev. 2000.

TRIGO, L. Turismo e qualidade: tendências contemporâneas. 2. ed. Campinas: Papirus, 1996.

WAINBERG, J. Cidades como sites de excitação turística. In: CASTROGIOVANNI, A. C. (Org.). Turismo urbano. São Paulo: Contexto, 2000.

YÁZIGI, E. A alma do lugar: turismo, planejamento e cotidiano em litorais e montanhas. São Paulo: Contexto, 2001. 